\title{
IEA 4E SSL annex: providing governments with the tools to accelerate market adoption of SSL products
}

\author{
Peter Bennich ${ }^{*}$, Nils Borg ${ }^{2}$ and Michael Scholand ${ }^{3}$
}

\author{
* Correspondence: peter.bennich@ \\ energimyndigheten.se \\ ${ }^{1}$ The Swedish Energy Agency, Box \\ 380 69, 10064 Stockholm, Sweden \\ Full list of author information is \\ available at the end of the article
}

\begin{abstract}
The SSL Annex was established in 2010 under the framework of the International Energy Agency's Energy Efficient End-use Equipment (4E) Implementing Agreement to provide advice to its ten member countries seeking to implement quality assurance programs for SSL lighting. This international collaboration brought together the governments of Australia, China, Denmark, France, Japan, The Netherlands, Republic of Korea, Sweden, United Kingdom and United States of America. China worked as an expert member of the 4E SSL Annex. The SSL Annex completed its first term in June 2014 and started on its second five-year term in July 2014.

During the first term, the Annex had undertaken three major collaborative tasks on (1) Quality Assurance, (2) SSL Testing and (3) Standards \& Accreditation. On quality assurance, the Annex worked to develop a set of performance tiers aimed to identify a suite of metrics and values related to minimum performance values of SSL for energy efficiency, lighting quality, and safety. Reports on SSL products and LCA aspects as well as SSL products and health aspects were developed within this task. For SSL Testing, the Annex has sought to promote harmonisation of SSL quality and performance testing around the world by establishing the world's largest interlaboratory comparison (IC 2013) of SSL laboratories with more than 110 laboratories compared around the world. And for Standards and Accreditation, the Annex worked to establish suitable accreditation frameworks for laboratories participating in IC 2013, promoting worldwide mutual recognition of PT.

The Annex started its second term in July 2014, and will run through June 2019. The new work plan continues some of the activities undertaken in the first term, but also tackles new challenges such as lifetime testing and market monitoring, verification and enforcement.
\end{abstract}

Keywords: Efficient lighting; Energy efficiency programmes; Solid state lighting; Interlaboratory comparison; Solid state lighting quality assurance

\section{Background}

The SSL Annex [1,2] was established in 2010 under the framework of the International Energy Agency's Energy Efficient End-use Equipment (4E) Implementing Agreement to provide advice to its ten member countries seeking to implement quality assurance programs for SSL lighting. This international collaboration brings together the governments of Australia, China, Denmark, France, Japan, The Netherlands, Republic of

\section{黛 Springer}

(c) 2015 Bennich et al.; licensee Springer. This is an Open Access article distributed under the terms of the Creative Commons Attribution License (http://creativecommons.org/licenses/by/4.0), which permits unrestricted use, distribution, and reproduction in any medium, provided the original work is properly credited. 
Korea, Sweden, United Kingdom and United States of America. China works as an expert member of the 4E SSL Annex.

The goal of the SSL Annex is to develop simple tools to help governments and consumers all over the world quickly and confidently identify which solid-state lighting (SSL) products have the necessary quality and performance levels to effectively reduce lighting energy demand. The Annex aims to work internationally to support the work that is being done on a national and regional level to address these and other challenges with SSL technologies.

The lack of agreement on test standards and lack of an international accreditation scheme creates trade barriers and increases overhead costs of doing business which will slow down the adoption of LEDs and result in lost energy savings. In each of the four regions shown in Figure 1, the present situation is shown where four different proficiency tests (PT) are used in each region to assess laboratory's competence for measuring the performance of LED lamps, and no other region accepts the test results from a different region.

One of the critical functions of the Annex is to address these issues and assist in establishing a consistent foundation on which lamps can be tested and compared, including mutual recognition of accreditation programmes across the various regional markets. Figure 2 represents an illustration of the ideal scheme that the SSL Annex is working to achieve.

The main activities of the Annex in the first term were divided into three specific work streams, Tasks 1, 2 and 3. Task 1 addressed quality assurance issues for LED lamps and luminaires and defined performance tiers for a number of different product categories [3-8]. Task 1 also gathered and analysed available information on environmental (LCA) [9] and health effects [10] of SSL technologies. Tasks 2 and 3 were closely related to each other, focused on the testing and accreditation of laboratories. Task 2 sought to develop a global interlaboratory comparison (IC) scheme $[11,12]$ to

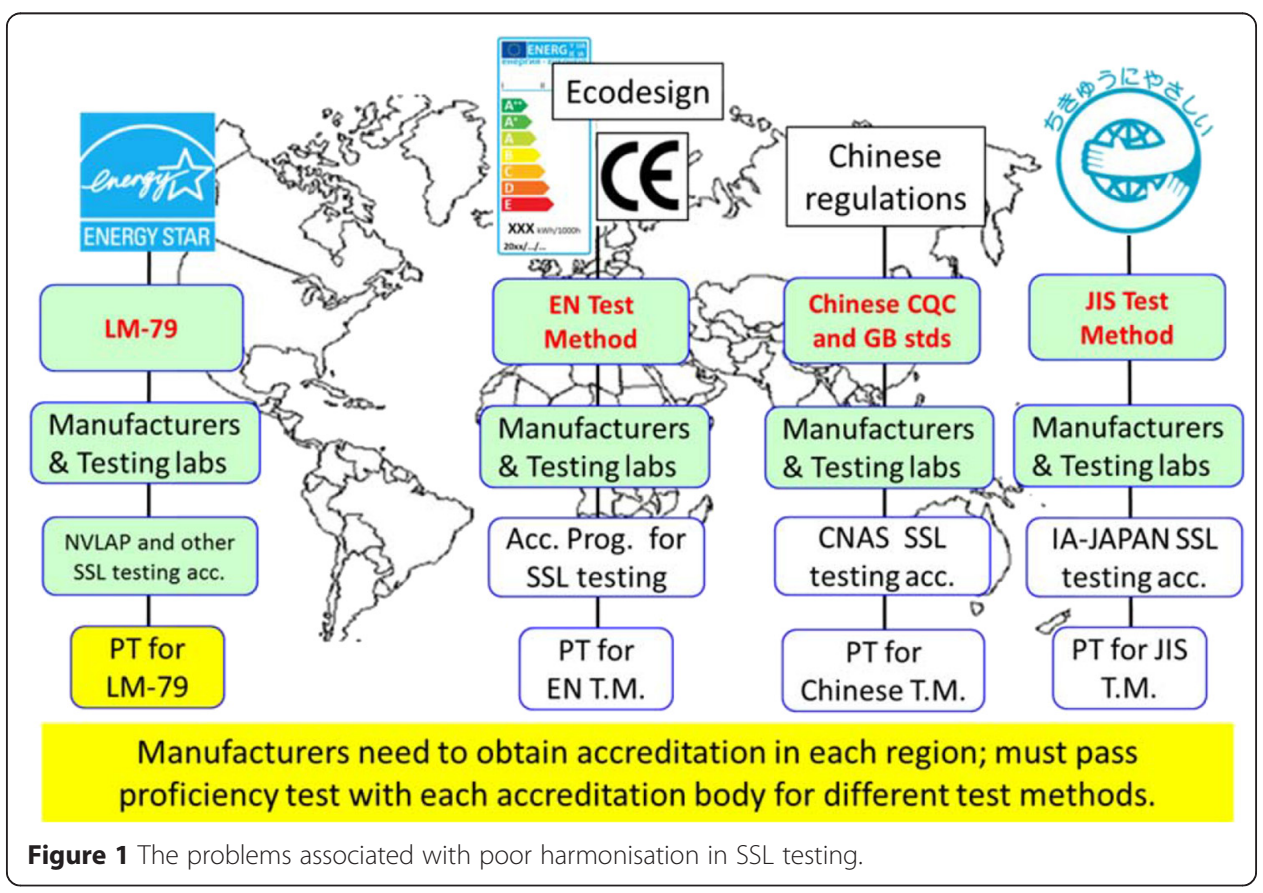




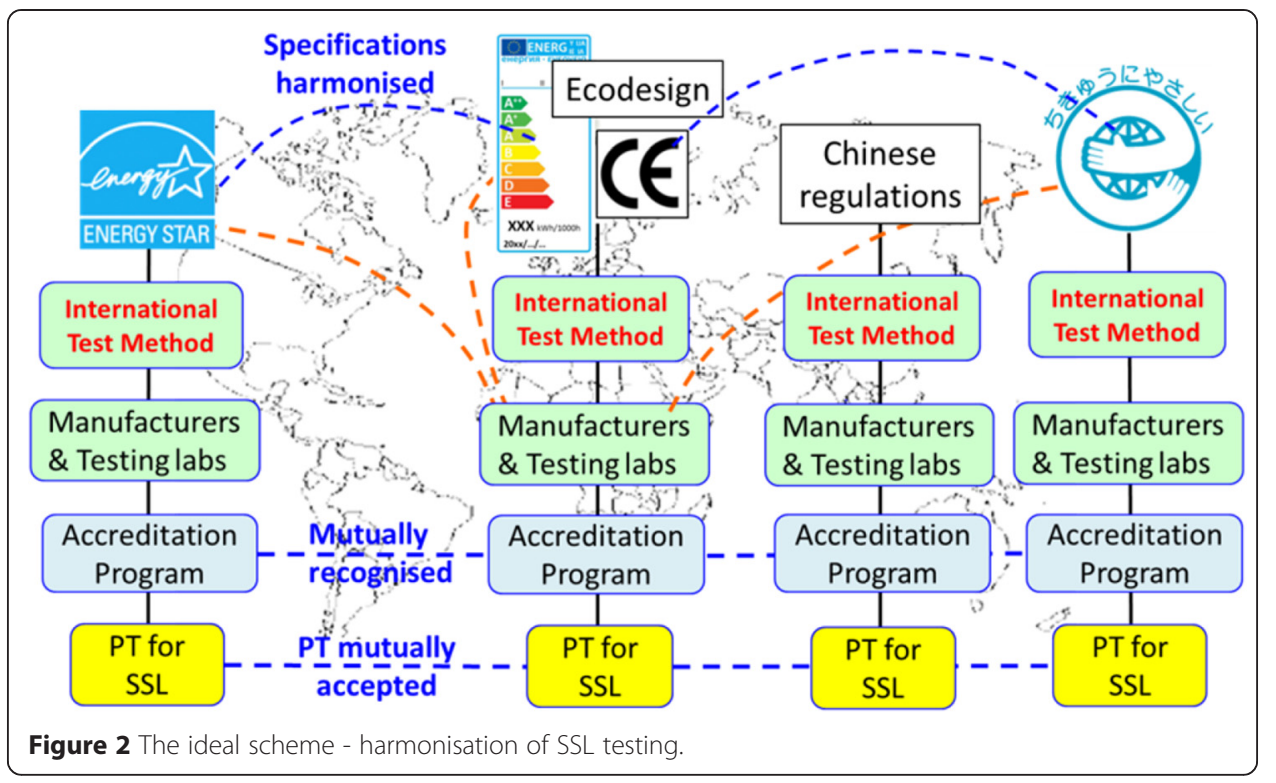

help support laboratories who are interested in applying for accreditation to testing LED products, as well as providing testing benchmarks for participating labs. This Task included the development of an interim test method [13] for the IC that was based on combining the most stringent requirements of regional test methods from around the world. The SSL Annex's 2013 Interlaboratory Comparison (2013 IC) programme involved 110 SSL laboratories globally, the largest IC for LED product laboratories to date. Task 3 worked to establish suitable accreditation frameworks [14,15] for laboratories participating in IC 2013, promoting worldwide mutual recognition of SSL proficiency testing. By using the results of the Task 2 test based on the SSL Annex test method, it is hoped that accreditation bodies can use the results of the 2013 IC as a proficiency test for a participating laboratory.

\section{First term task 1: develop SSL quality assurance}

All of the Annex's First Term Task 1 activities were led by Dr. Georges Zissis from Toulouse University in France. Task 1 was focused on developing generic performance tiers for various SSL products as well as making life-cycle assessment and health impact analyses of SSL products. Under Task 1 the SSL Annex published SSL performance tiers for the following products:

- Non-directional Lamps for Indoor Residential Applications [3]

- Directional Lamps for Indoor Residential Applications [4]

- Downlight Luminaires [5]

- Replacement (retrofit) Linear Fluorescent LED Lamps [6]

- (Non-retrofit) Linear Fluorescent LED Lamps [7]

- Street Lighting/Outdoor Lighting [8]

For each of these products, several performance tier levels were set to address the various priorities and needs from each country. The performance tiers contain 
requirements for luminous efficacy, colour temperature and tolerance, chromaticity tolerance, colour maintenance, colour rendering index, lag start time, lumen maintenance, lamp lifetime, flicker, power factor, harmonic distortion, endurance test and other factors.

Task 1 was designed to help governments define minimum quality requirements in policy measures for SSL products. These requirements could be for bulk procurement contracts and incentive schemes, or national energy policies, standards and labelling programmes. The SSL Annex continues to monitor the market and the appropriateness of these published tier levels, and expects that additional levels will be added in the future as SSL technology advances. It should be noted that these performance tiers are not intended to be international standards or to be adopted as mandatory energy or performance regulations, but are aimed as a guide that provides unbiased information on realistic SSL performance levels. Given that similar guidance is not currently available in international standards this guidance should be useful to both member countries and the broader community.

Task 1 culminated in the preparation of two Final Reports that were published and placed in the public domain. They were:

- Life-Cycle Assessment Final Report [9] - published 17 September 2014. A comprehensive review of all the current life-cycle assessment studies on Light Emitting Diode (LED) lamps and luminaires compared with conventional lighting technologies. This review found that the energy in use is the dominant environmental impact of lighting systems, thus energy-efficient LED systems represent an opportunity to significantly reduce the impact of illuminating our buildings and outdoor areas.

- Health Impacts Study Final Report [10] - published 24 September 2014. A comprehensive review of the current literature relating to human health impacts of solid-state lighting (SSL). This review evaluates whether energy-efficient LED systems are a safe light source to illuminate our homes, buildings and outdoor areas. The review concluded that SSL technology is not expected to have more direct negative impacts on human health with respect to non-visual effects than other lighting technologies. For electromagnetic fields, human exposure emitted by SSL products does not appear to be a critical issue as their magnitude is generally much smaller than those corresponding to discharge lamps or certain household appliances. The report also provides advice on flicker and glare.

\section{First term task 2: harmonise SSL performance testing}

All of the Annex's First Term Task 2 activities were led by Dr. Yoshi Ohno of the National Institute of Standards and Technology (NIST) in the USA. Task 2 worked to support the harmonisation of SSL testing around the world, developing an approach to compare and provide support for the accreditation of laboratories for their ability to measure LED products. The underlying motive for Task 2 was the fact that testing of SSL products is, in many ways, different from testing conventional light sources and a lab that can reliably test conventional light sources may not necessarily be able to provide accurate test results for SSL products. 
Task 2 was built around four so-called Nucleus Laboratories: the National Institute of Standards and Technology (NIST) in the USA; the National Lighting Test Centre (NLTC) in China; the National Metrology Institute of The Netherlands (VSL) in The Netherlands; and the National Metrology Institute Japan in National Institute of Advanced Industrial Science and Technology (AIST, NMIJ) in Japan. Each of these nucleus laboratories served as a regional reference lab for a group of laboratories to be tested. In total, 110 laboratories were compared in this international comparison. Some of the positive outcomes that may be the result of the SSL Annex undertaking Task 2 are listed below:

- Lower development costs for preparing test methods, especially for emerging technologies such as SSL products;

- More accurate and comparable test results for products sold domestically and in neighbouring economies;

- The opportunity for participating laboratories to apply to their local accreditation bodies to be accredited to a test standard for LED lamps;

- The ability to transpose and adapt analyses from other markets to determine appropriate domestic efficiency requirements; and

- Faster and less expensive testing - for compliance and other purposes - as harmonised testing creates a larger choice of laboratories who can conduct product tests.

\section{First term task 3: standards and accreditation}

All of the Annex's First Term Task 3 activities were led by Dr. Koichi Nara of the National Institute of Advanced Industrial Science and Technology in Japan. Task 3 was focused on disseminating the results of Task 2, and supporting laboratories who wish to apply for LED lamp testing accreditation to their respective accreditation bodies. In the design and implementation of 2013 Interlaboratory Comparison (IC 2013), the Annex agreed to conform to ISO/IEC $17043[14,15]$. The four Nucleus Laboratories are all National Metrology Institutes or National Testing Institutes and possess their own primary measurement standards and have developed a measurement method and validated it. All of the relevant measurement services carried out by them were accredited by International Laboratory Accreditation Cooperation Mutual Recognition Agreement (ILAC/MRA) signatories or peer reviewed against ISO/IEC 17025 and registered to Appendix-C in the CIPM/MRA (Comité international des poids et measures MRA). Therefore, the basic competence of the institutions related to the measurements has been established.

In the absence of a global test method, it has not been possible for the international accreditation system to be set up a system for mutual recognition of regional accreditation programmes. It has been difficult for many Accreditation Bodies (ABs,) to carry out SSL Proficiency Testing (PT) as part of their ISO/IEC 17025 accreditation. While some ABs like CNAS (in China) or NVLAP (a US accreditation programme) carry out SSL PT or comparison test, the test is not within the scope of the ILAC MRA, and thus it is not possible for these PTs to be accepted globally. Due to the global fragmentation and disparities in SSL test methods, accreditation and PT for SSL products has been held back. In the future, a robust programme for SSL PT could be established based on 
an international test method, such as the CIE standard discussed above [16]. Countries would then choose whether to harmonise to this test standard based on its own needs and regulatory requirements, enabling worldwide mutual recognition of SSL product testing and laboratory accreditation. Figure 3 illustrates how accreditation for regional methods can be based on a common, global test method, and how the test method [13] used in the IC 2013 has served as an interim for such a global method.

\section{Launching the second term}

The following is a summary of the 5-year workplan (from 1 July 2014 - 30 June 2019) for the SSL Annex. The workplan consists of eleven tasks in the SSL Annex, ten focusing on core activities and one on cross-cutting communications and outreach. Figure 4 offers an overview of the tasks and Tasks, and the following text provides a summary of the anticipated work. All of the SSL Annex work will continue to be focused on providing support to policy makers, government authorities and programme managers who are addressing issues relating to SSL in their respective markets.

Task 1. Application of new CIE Test Method - the CIE TC2-71 test method standard became available as a DS (Draft Standard) in September 2014, was accepted as a CIE standard in March 2015 [16] and will later possibly also be accepted as a joint CIE/IEC standard. The Annex welcomes this new effort, but some questions arise as to what extent the new CIE test method can be applied by governments for MV \& E and other testing needs. This task looks at the application and relevance of the new test standard to determine its potential to be used as a test standard for governments and product regulators. This study would help address questions like: which parameters can it test, how reliable are the results, what sample sizes are necessary, what tolerance values are assigned to measurements, and so on. The main output from this task will be a report that discusses the findings of the evaluation and a recommendation on how the new test standard can be used effectively by governments.

Task 2. Characterisation of Product Lifetime - this activity works to understand the lifetime issues of LED products. The task does not envisage the Annex doing primary research, but instead will be conducted as a meta-study based on papers
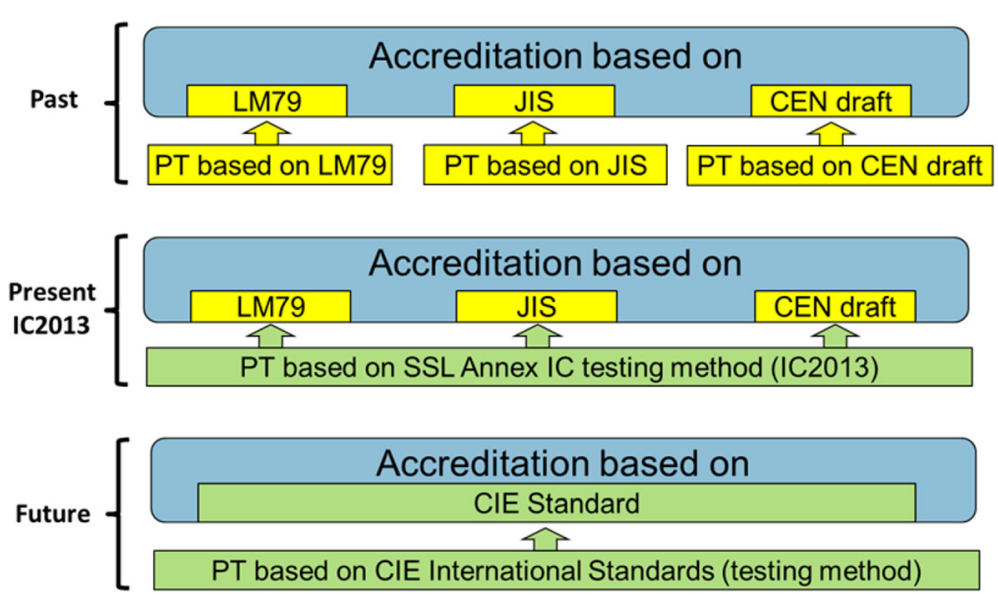

Figure 3 SSL annex IC2013 serves as an interim solution for laboratory accreditation. 


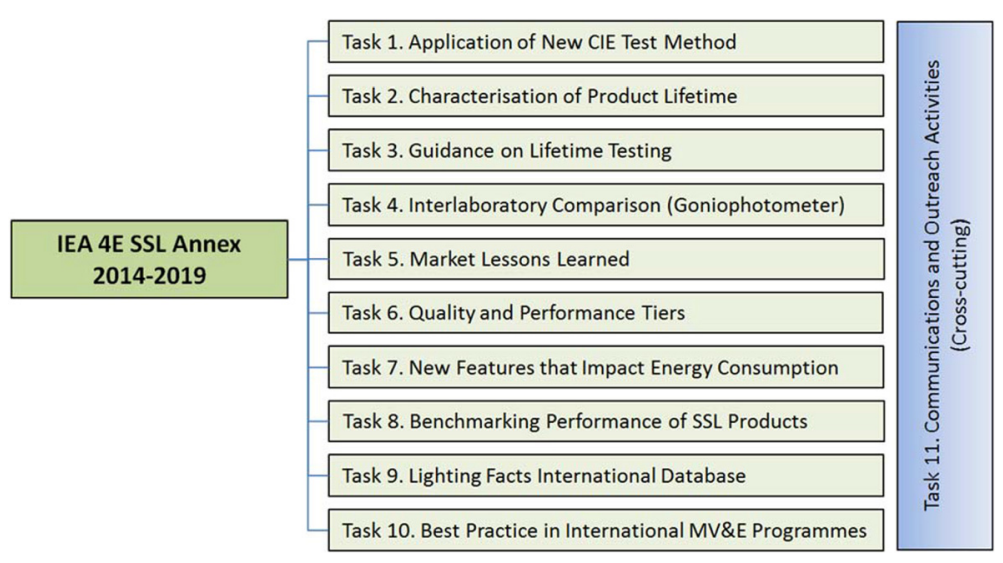

Figure 4 SSL annex tasks workplan for second term, 2014-2019.

published by academic researchers, international associations/societies (e.g., IES, CIE, etc.) and testing laboratories. This task will synthesise the information to help policy makers make decisions on SSL product lifetime. The Annex will prepare a summary of the findings explaining key features in defining, evaluating and testing for product lifetime in a format that is accessible and provide policy guidance. This task will not resolve the complexities of lifetime testing, but it is expected to provide greater understanding of the context and options, and contribute to the discussion through the development of an agreed position for policy-makers on the lifetime of LED products.

Task 3. Guidance on Lifetime Testing - this study will review the existing test methods for determining luminous flux maintenance and colour maintenance of SSL products (available from IEC SSL product performance standards and regional test method standards on SSL products and their components) and provide guidance to member country governments on lifetime testing of SSL products. It is therefore linked to Task 2 (Characterisation of Product Lifetime), but this task will focus on how to test the specific photometric aspects of SSL product lifetime.

Task 4. Interlaboratory Comparison (Goniophotometer) - this task will be to design and conduct a new global interlaboratory comparison test programme with the Nucleus Laboratories using a new artefact set including directional lamps (requiring use of a goniophotometer for measurement of useful flux or other flux definition according to beam angle, angular colour uniformity), light engines (e.g., Zhaga Consortium modules, etc.) and road/street lighting luminaires, which could not be included in the SSL Annex's Interlaboratory Comparison 2013 (IC2013). This task would also provide support for any follow-up work related to IC2013.

Task 5. Market Lessons Learned - this task will work to review the lessons learned by Annex member governments on the introduction of SSL products, including how the markets developed and evolved, extracting lessons learned and pitfalls to avoid (i.e., not repeating the mistakes surrounding the introduction of new technologies). Two reports are foreseen: one in year one and one update in year four (or five) of the Annex's term. The report is to support policy makers in making appropriate choices as they work to promote quality SSL products in their respective markets.

Task 6. Quality and Performance Tiers - this activity promotes the harmonisation of voluntary and mandatory programme performance requirements for SSL products 
around the world. Covering both lamps (e.g., non-directional lamps) and luminaires (e.g., street light luminaires), this activity seeks to maintain and perhaps slightly expand the Annex's current set of products for which there are three performance tiers - from minimum quality to best in market. This task also includes reviewing the latest literature on life-cycle assessment and health-related issues, as this may impact the tier levels. Off-grid lighting product performance recommendations will be retained and developed where applicable as a separate document.

Task 7. New Features that Impact Energy Consumption - LED products offer a number of opportunities to bring new features to the market that are not commonly associated with lighting technologies. These may be user-focused features such as colour-tunability and network access to controls, or features that are intended to prolong life and function of products such as active thermal control or regulation of drive current to maintain flux over time. This activity focuses on identifying and measuring the energy consumption (such as stand-by power) associated with some of the new features that are being incorporated into SSL products.

Task 8. Benchmarking Performance of SSL Products - this Task will establish an internal benchmark performance database of SSL products to enable the sharing of 1) claimed performance data and 2) test results on these products sampled and tested by accredited, independent laboratories. This internal database would be for Annex member governments only and would consist of data generated primarily through member government testing programmes. The database would have a limited set of criteria, based on the new CIE test standard [16], and will provide member governments with an on-going, independent assessment of SSL product performance over time. Six-monthly briefings for member countries will be published that query the database and extract information on the trends. This sixmonthly briefing will also contain and compare with data from Lighting Facts International (Task 9).

Task 9. Lighting Facts International Database - this Task will work to make the US DOE's Lighting Facts database into a global platform that any government can opt-in to use it for domestic SSL promotion programmes through customised, country-specific user interfaces. The resulting Lighting Facts International database would follow the same quality control criteria of Lighting Facts. The database will be refreshed and updated on an on-going basis, and it will be used as input for a sixmonthly briefing on product trends described under Task 8 . This task may be coordinated in partnership with the Global Lighting Association, who expressed interest in the Annex supporting MV\&E programmes globally. Note: The Lighting Facts International database is fundamentally different from the benchmarking performance database (Task 8) above. Lighting Facts International will be dependent on a supplier wanting to input its product data into the database and being willing to have the product tested on request. The benchmarking performance database in Task 8 is based on government agency input and kept as a resource for internal use only.

Task 10. Best Practice in International MV\&E Programmes - this Task intends to help member governments develop more cost-effective and efficient Monitoring, Verification and Enforcement (MV\&E) activities. This task focuses on gathering and sharing information and best practice on MV\&E programmes globally. The output from this work is intended to serve as a guide for policy makers in countries who want to learn 
from the experience of running MV\&E in other countries, including information on cost, test methods, sample sizes, performance metrics, results variability and so-on.

Task 11. Communications and Outreach Activities - this is a cross-cutting communications and outreach activity which is intended to formalise a strategy targeting four key groups - (1) policy-makers and regulators; (2) standardisation bodies; (3) international lighting organisations and (4) lighting industry - to try and promote the work of the SSL Annex. In addition, NGOs and consumer organisations are seen as relevant targets groups for information from the SSL Annex. This task involves raising awareness amongst the relevant decision makers on SSL product quality, market support and test standard harmonisation. This task involves both general and specific communications activities that will engage experts and decision-makers in the market to make them aware of the Annex's work.

\section{Discussion and conclusions}

The SSL Annex serves as an excellent case study for the benefits of international cooperation around the introduction of a new, energy-efficient technology. The Annex participants have found there are significant advantages to engaging in collaboration between member countries to promote a consensus on harmonised approaches to SSL quality and performance. The output of the Annex collaboration can be used, for example, to establish national government policy on SSL quality and performance levels while also benefitting industry by facilitating a harmonisation across national programmes and requirements (avoiding the costly problem of a patchwork of different regulations). The tiered performance requirements developed by the Annex can, for instance, be used as the basis for national or regional minimum performance requirements that help protect both the consumer and the reputation of SSL as a reliable, efficient and quality lighting product. Where possible, harmonised minimum performance requirements and higher voluntary levels can ensure that a broad range of quality products are available to consumers in many countries.

The Annex itself is a forum for regular discussion of challenges and issues that policy-makers face when working with SSL. This forum facilitates the exchange of ideas, test results, campaign methods, the ability to discuss issues around regulations and enforcement challenges; and to share best practices on voluntary and regulatory programmes designed to accelerate market adoption of SSL technology.

The Annex completed its first term work programme in mid-2014 and launched a second term of the SSL Annex for a further five more years to continue the existing work and take on new responsibilities that will support the market and member countries.

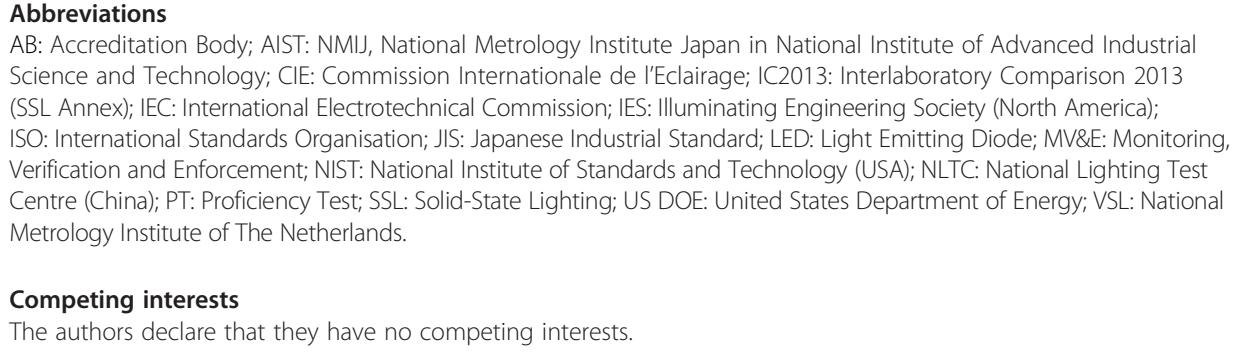




\section{Acknowledgements}

The Authors would like to thank the governments of Australia, China, Denmark, France, Japan, Korea, Sweden, the United Kingdom and the United States for their sponsorship of the SSL Annex and their on-going support in overseeing and guiding the activities of the Annex. The work of the SSL Annex depends on the in-kind contributions from these member governments, including their policy and technical experts involved in solid-state lighting. In particular, the authors would like to acknowledge and thank Dr. Georges Zissis, Task 1 Leader; Dr. Yoshi Ohno, Task 2 Leader; and Dr. Koichi Nara, Task 3 Leader.

Thematic Series on 14th International Symposium on the Science and Technology of Lighting held in Como, Italy, between 22nd and 27th June, 2014.

\section{Author details}

${ }^{1}$ The Swedish Energy Agency, Box 380 69, 10064 Stockholm, Sweden. Borg \& Co AB, Sveavagen 98,11350 Stockholm, Sweden. ${ }^{3}$ N14 Energy Limited, 42 Conway Road, London N14 7BE, UK.

Received: 2 December 2014 Accepted: 20 April 2015

Published online: 07 May 2015

\section{References}

1. IEA 4E SSL annex. See http://ssl.iea-4e.org/.

2. Bennich P, Borg N, Scholand M (2013) On the bright side of life: International efforts to accelerate market adoption of LEDs while avoiding the pitfalls of CFLs. In: Proceedings of eceee 2013 Summer Study, Club Belambra Les Criques, Presqu'île de Giens, Toulon/Hyères, France, 3-8 June 2013.

3. Annex SSL. Solid State Lighting Annex: Product Quality and Performance Tiers: Non-Directional Lamps. Stockholm: Sweden; 2014.

4. Annex SSL. Solid State Lighting Annex: Product Quality and Performance Tiers: Directional Lamps. Stockholm: Sweden; 2014.

5. Annex SSL. Solid State Lighting Annex: Product Quality and Performance Tiers: Downlights. Stockholm: Sweden; 2014

6. Annex SSL. Solid State Lighting Annex: Product Quality and Performance Tiers: Fluorescent Tubes (Retrofit). Stockholm: Sweden; 2014.

7. Annex SSL. Solid State Lighting Annex: Product Quality and Performance Tiers: Fluorescent Tubes (Non-Retrofit). Stockholm: Sweden; 2014

8. Annex SSL. Solid State Lighting Annex: Product Quality and Performance Tiers: Outdoor Lighting (Street Lighting). Stockholm: Sweden; 2013.

9. SSL Annex. Solid State Lighting Annex: Life Cycle Assessment of SSL. Final Report. Stockholm, Sweden: SSL Annex Task 1; 2014h.

10. SSL Annex. Solid State Lighting Annex: Potential Health Issues of SSL. Final Report. Stockholm, Sweden: SSL Annex Task 1; 2014i.

11. Annex SSL. Solid State Lighting Annex: Summary Report of Nucleus Laboratory Comparison - Final Report. Sweden: Stockholm; 2012.

12. SSL Annex. Solid State Lighting Annex: 2013 Interlaboratory Comparison, Final Report. Stockholm, Sweden: SSL Annex Tasks 2 and 3; 2014g.

13. SSL Annex (2012f) Solid State Lighting Annex: Interlaboratory Comparison Test Method, Version 1.0. Stockholm, Sweden.

14. Annex SSL. Solid State Lighting Annex: Interlaboratory Comparison Generic Protocol. Stockholm: Sweden; 2012

15. SSL Annex (2012f) 2013 Interlaboratory Comparison, Quality Policy Document (Version 1.0). Stockholm, Sweden.

16. CIE S 025/E:2015: Test Method for LED Lamps, LED Luminaires and LED Modules.

Submit your manuscript to a SpringerOpen ${ }^{\circ}$ journal and benefit from:

- Convenient online submission

- Rigorous peer review

- Immediate publication on acceptance

- Open access: articles freely available online

- High visibility within the field

- Retaining the copyright to your article 